\title{
Recent Advances in the Management of Hormone-Sensitive Oligometastatic Prostate Cancer
}

\author{
Giulia Marvaso (D) 1,2,* \\ Stefania Volpe (D) ${ }^{1,2, *}$ \\ Matteo Pepa (iD) ${ }^{1, *}$ \\ Mattia Zaffaroni ${ }^{1, *}$ \\ Giulia Corrao ${ }^{1,2, *}$ \\ Matteo Augugliaro ${ }^{1, *}$ \\ Franco Nolè ${ }^{3, *}$ \\ Ottavio De Cobelli ${ }^{2,4, *}$ \\ Barbara Alicja Jereczek- \\ Fossa (iD) ${ }^{1,2, *}$ \\ 'Division of Radiation Oncology, IEO \\ European Institute of Oncology IRCCS, \\ Milan, Italy; ${ }^{2}$ Department of Oncology \\ and Hemato-Oncology, University of \\ Milan, Milan, Italy; ${ }^{3}$ Medical Oncology \\ Division of Urogenital \& Head \& Neck \\ Tumors, IEO European Institute of \\ Oncology IRCCS, Milan, Italy; \\ ${ }^{4}$ Department of Urology, IEO, European \\ Institute of Oncology IRCCS, Milan, Italy \\ *These authors contributed equally to \\ this work
}

\begin{abstract}
After primary treatment for prostate cancer with either radical prostatectomy or radiotherapy, a significant proportion of patients are at risk of developing metastases. In recent years, a deeper understanding of the underlying biology together with improved imaging techniques and the advent of new therapeutic options including metastasesdirected therapies and new drugs have revolutionized the management of low-burden metastatic disease, also known as oligometastatic state. The purpose of this narrative review is to report the recent developments in the management of hormone-sensitive oligometastatic prostate cancer patients.
\end{abstract}

Keywords: oligometastatic prostate cancer, metastasis-directed therapies, narrative review, imaging, biology

\section{Introduction}

Until recently, the oligometastatic state was considered as an intermediate condition in the stepwise process of metastatic progression. ${ }^{1-3}$ This paradigm has revolutionized the concept of metastatic disease, thus encouraging the use of localized therapeutic approaches in patients presenting with low-burden lesions. Meantime, effort has been put to identify the underlying biological mechanisms for the identification of genomic alterations specific between widespread metastatic disease and limited metastatic burden. ${ }^{4}$ Under the hypothesis of different biological states, it is even more critical to discriminate between these disease entities, to identify which patients are more likely to benefit from curative-intent therapies.

The application of these concepts is of peculiar interest for prostate cancer (PCa). On the one hand, the advent of novel imaging modalities, eg 18F- 11C choline positron emission tomography/computed tomography (PET/CT) and 68Gaprostate-specific membrane antigen (PSMA) PET/CT, is facilitating the diagnosis of patients in the oligometastatic state. On the other hand, the availability of novel therapeutic approaches is providing clinicians with a wider set of treatment options, which can be both of local (eg stereotactic body radiotherapy, SBRT) and/or systemic nature (eg immunotherapy, second generation antiandrogens and radiopharmaceuticals). ${ }^{5}$ Considering the increasing interest towards metastasisdirected radiotherapy, a recent consensus from the European SocieTy for Radiotherapy and Oncology/American Society for Radiation Oncology (ESTRO/ ASTRO) has concluded that, to fit the definition of "oligometastatic", the total
Correspondence: Matteo Pepa

Division of Radiation Oncology, IEO,

European Institute of Oncology IRCCS,

Milan, Italy

Email matteo.pepa@ieo.it 
number of detectable lesions should be less than 5 , and all of them should be safely treatable, regardless of the control of the primary tumor. ${ }^{6}$

Nevertheless, a universally accepted definition of oligometastatic PCa (OMPC) is still under debate. To better clarify this concept, the 2019 Advanced Prostate Cancer Consensus Conference (APCCC) has discussed the main criteria for the definition of OMPC, which include the following: number of lesions, location of the involved metastatic sites (nodes vs bone and/or visceral), time of onset (synchronous vs metachronous) and castration status. ${ }^{7}$ While consensus was not reached among panelists for a definition of OMPC, they agreed that conventional imaging (namely, CT and bone scintigraphy) can no longer be considered sufficient for the (re)staging of suspected OMPC. Specifically, for metachronous disease - which will be the focus of the present work - the current recommendation is to perform a PSMA PET/CT to confirm the oligometastatic state, although the management of false negative and false positive findings is still debated. ${ }^{8}$ Being the use of the sole prostate specific antigen (PSA) increasingly questioned, a stronger level of evidence is warranted to define the optimal pathway of care in this subset of patients, which includes the impact of nextgeneration imaging (NGI) on treatment outcomes, the combination of local and systemic approaches and followup scheduling.

While results from ongoing trials are awaited, our work aims to present a critical and comprehensive overview of the state of art for hormone-sensitive OMPC.

In the present work, we will start by considering the rationale behind metastasis-directed therapies (MDTs) in the light of the use of novel imaging modalities, which will be presented together with more established techniques in the fields of both radiology and nuclear medicine. Subsequently, we will discuss current preliminary results for systemic therapies in the oligometastatic hormonesensitive setting. Finally, our work will provide an overview on potential biomarkers which, arguably, could bring complementary information to image findings in the individualized definition of the true oligometastatic state.

\section{Emerging Evidence on SBRT as a Promising MDT}

A recent metanalysis reporting results from prospective and randomized trials have showed that OMPC patients could potentially benefit from MDT approaches. ${ }^{9}$
Specifically, in the setting of oligo-recurrent hormonesensitive PCa, several retrospective studies and Phase II/ III randomized trials suggest that MDT has a positive impact on oncological outcomes with an acceptable associated toxicity profile. ${ }^{10}$ The purpose of these interventions is to improve disease control, contain metastatic progression, delay the start of systemic therapies and eventually improve survival. ${ }^{11}$ Although several forms of MDTs exist, including radiofrequency ablation, cryotherapy, salvage lymph node dissection, metastasectomy and radiotherapy, the latter is often preferred. To start with, it is a non-invasive modality which does not require neither anaesthetizing nor hospitalization. ${ }^{12}$ Additionally, it is a cost-effective and well-tolerated therapy, provided that facilities and adequately trained personnel are available. Radiotherapy is usually delivered with two different approaches, namely elective nodal radiotherapy (ENRT), which consists in irradiating bilaterally the whole pelvic region and SBRT, which treats exclusively the nodal relapse in the attempt to reduce side effects. A retrospective analysis on 506 patients by De Bleser et al, ${ }^{13}$ comparing ENRT and SBRT across multiple institutions, confirmed that the former is associated not only with a longer 3-year metastasis-free survival (77\% vs $68 \%, p=0.01$ ) but also with more frequent late toxicity events $(18 \%$ vs $6 \%, \mathrm{p}=0.002)$. A recent review by Rogowski et $\mathrm{al}^{8}$ considered 56 studies between 2012 and 2020 with the purpose to provide an overview of the role of MDTs in OMPC. The authors concluded that MDT was associated with high local control rates (22-83\%) with low morbidity and that a relevant proportion of patients was free of progression after 2 years. Another important desired objective of MDT strategies is to prolong androgen deprivation therapy (ADT)-free survival. This benefit was confirmed by Ost et al who reported ADT-free survival of 21 months in the MDT group vs 13 months in the surveillance group. ${ }^{14}$ The above-mentioned meta-analysis, considering a total of 445 patients treated with MDTs, considers the available evidence on the role of SBRT in OMPC. ${ }^{9}$ Other than confirming a clear benefit of SBRT over observation in terms of local and biochemical control, results also demonstrated that such benefit was maintained over time (24 months after baseline). The integration of MDT into personalized pathways of care is even more appealing if one considers that most ADT-sensitive patients will progress towards a castration-resistant state in the course of their life. ${ }^{11}$ As a consequence, the integration of MDTs in selected patients' care pathway could 
represent a valuable option to delay the start of systemic therapies and its associated side effects. However, radiotherapy approaches are still far from being routinely implemented in clinical practice, as more solid data on its long-term efficacy needs to be confirmed, especially in terms of overall survival (OS). ${ }^{15}$

\section{Imaging in OMPC}

For years, serum PSA increase after primary treatment represented the main trigger for identifying disease progression and selecting the optimal therapy. With no or little information on presence, localization and burden of metastatic disease, under- and over-treatment as well as associated side effects were common. ${ }^{11}$ Recently, a variety of imaging techniques were proposed to complement PSA measurements and define metastatic active lesions. ${ }^{11}$ Accordingly, the latest National Comprehensive Cancer Network (NCCN) and European Association of Urology, ESTRO, and International Society of Geriatric Oncology (EAU-ESTRO-SIOG) guidelines recommended the employment of the most recent imaging modalities to restage patients with PSA rise, suspect of biochemical relapse after curative treatments. ${ }^{16}$. The identification of location and extent of metastatic disease in PCa patients using both cross-sectional, ie CT and magnetic resonance imaging (MRI), and planar imaging techniques, such as Technetium $99 \mathrm{~m}$-methylene diphosphonate ( ${ }^{99 \mathrm{~m}} \mathrm{Tc}-\mathrm{MDP}$ ) bone scintigraphy, ${ }^{1,12}$ represents a crucial step in the current clinical practice. All these modalities are widely available and affordable and allow for whole body imaging. However, they show only a modest diagnostic accuracy, with CT and bone scan having a sensitivity in the 70 $80 \%$ and $60-80 \%$ ranges, respectively. ${ }^{17}$ Specifically, performances of $\mathrm{CT}$ in discriminating between pathological and reactive lymph nodes can be as low as $40 \%$, especially when their dimension is comparable. ${ }^{18} \mathrm{CT}$ has also a modest accuracy in detecting bone metastases, as small lesions of the bone and fatty marrow are difficult to be distinguished. On the other hand, bone scintigraphy represents the most widely used method for assessment of bone lesions. The addition of single-photon emission computed tomography (SPECT) or SPECT/CT to planar imaging appears to slightly improve its diagnostic precision, ${ }^{16}$ with a meta-analysis reporting a $3 \%$ rise in combined sensitivity and specificity when SPECT is employed (79 vs $82 \%) .{ }^{19}$ Although conventional imaging techniques still represent a valid and established option in the setting of OMPC, they have limited ability to precisely identify and estimate the location and extent of metastatic lesions. ${ }^{16}$ In recent years, the awareness of these limitations has resulted in a growing interest towards NGI techniques, and to the development of novel PET radiotracers to better target lesions of bone and soft tissue, ${ }^{1}$ with the aim of revealing submerged disease with improved sensitivity and specificity. ${ }^{10}$ Particularly attractive are radiotracers targeting directly cancer cells (eg carbon $11\left({ }^{11} \mathrm{C}\right)$-choline, ${ }^{18} \mathrm{~F}$-fluoroethylcholine $\quad\left({ }^{18} \mathrm{~F}-\mathrm{Cho}\right)$, trans-1-amino-3-${ }^{18} \mathrm{~F}$-fluorocyclobutanecarboxylic-acid $\left.\left({ }^{18} \mathrm{~F}-\mathrm{FACBC}\right)\right)$ and those targeting PSMA cell surface protein (eg Gallium 68 ( $\left.{ }^{68} \mathrm{Ga}\right)-\mathrm{PSMA}-11$ and 2-(3-\{1-carboxy-5-[(6- $\left[{ }^{18} \mathrm{~F}\right]$ fluoro-pyridine-3-carbonyl)-amino]-pentyl $\}$-ureido)pentanedioic acid) ${ }^{18} \mathrm{~F}$-DCFPyL). All these PET-based techniques were proven to be more sensitive in the identification of the oligometastatic disease when anatomical imaging is combined. ${ }^{12}{ }^{11} \mathrm{C}$ and ${ }^{18} \mathrm{~F}$ choline are radiolabeled choline derivatives able to detect increased cell membrane turnover. ${ }^{16}$ The choline-based method shows an unprecedented sensitivity and specificity in evaluating disease recurrence, with values as high as $85 \% .^{12}$ However, at low PSA levels, sensitivity decreases significantly. In general, this technique was proven to be more accurate in detecting bone metastases than lymph node lesions, with relatively high false positives rates for the latter. Diagnostic performances depend also on the specific choline derivative, with ${ }^{18} \mathrm{~F}$-choline outperforming ${ }^{11} \mathrm{C}$-choline (reported sensitivity and specificity of $62 \mathrm{vs}$ 92\%, respectively). ${ }^{16}$ The interest towards PSMA-targeted imaging has increased during the last years, as, thus far, it was proven to have the highest metastases detection rates over the other available imaging methods. ${ }^{8}$ In particular, studies showed ${ }^{68}$ Ga-PSMA PET/CT consistently outperforming choline PET/CT at low PSA values, ${ }^{20}$ with reported detection rates of $15-58 \%, 25-73 \%, 69-100 \%$ for PSA ranges of $0.2-0.5 \mathrm{ng} / \mathrm{mL}, 0.5-1 \mathrm{ng} / \mathrm{mL}$ and $1-2$ $\mathrm{ng} / \mathrm{mL}$, respectively. ${ }^{8}$ Moreover, a high level of interobserver agreement was demonstrated for ${ }^{68} \mathrm{Ga}$-PSMA PET/ CT, both for nodal and bony lesions. ${ }^{21,22}$

Admittedly, PSMA-based techniques may fail to detect clinical progression when PSMA is either absent or scarcely expressed. Although no definitive evidence of superiority of ${ }^{68} \mathrm{Ga}$-PSMA PET/CT exists, in the 2017 APCCC, the panelists recommended the use of ${ }^{68} \mathrm{Ga}$-PSMA PET/ CT to confirm the diagnosis of oligometastases after primary treatment. ${ }^{23}$

Another promising PET radiotracer is ${ }^{18} \mathrm{~F}$-fluciclovine, a synthetic amino acid approved for use in USA and 
Europe in $2016^{24}$ and $2017,,^{25}$ respectively, for men with PCa biochemical recurrence. ${ }^{26}$ The LOCATE trial (NCT02680041), investigating the role of such methods on the treatment of recurrent PCa patients, demonstrated that even at low PSA levels, ${ }^{18} \mathrm{~F}$-fluciclovine-PET/CT succeeded with the identification of recurrences missed with conventional imaging and that this frequently required major changes to radiotherapy treatment plan. With one quarter of patients diagnosed with OMPC, this method has the potential of guiding targeted therapies, however further investigations are necessary before it can be routinely adopted in the clinical practice. ${ }^{27}$

Other than nuclear medicine imaging modalities, whole body (WB)-MRI represents another valid option to quantify PCa metastatic burden. Similarly to the previously described techniques, WB-MRI could be a game changer in adequately selecting candidates for MDTs. ${ }^{17}$ Its most attractive feature consists in its capability to depict oligoprogressive metastatic lesions without exposing the patient to ionizing radiations. ${ }^{11}$ Several MRI sequences, including T1-weighted, T2-weighted, dynamic contrast-enhanced (DCE), diffusion-weighted imaging (DWI), can be successfully used to map the full extent of the disease. ${ }^{11,21}$ A study by Shen et al demonstrated that WB-MRI outperforms choline-PET in detecting bone metastases in terms of sensitivity (97 vs $91 \%$ ) but not in terms of specificity (95 vs 99\%). ${ }^{19}$ The adoption of novel contrast agents could help increasing detection capability, as shown by a recent meta-analysis that reported augmented diagnostic performances of DWI when ultra-small superparamagnetic iron oxide (USPIO) contrast agent is employed. ${ }^{28}$ Finally, in recent years, international guidelines have been published which provide indications for standardising acquisition, interpretation and reporting of WB-MRI. ${ }^{29}$

A recent meta-analysis by Farolfi et al, ${ }^{22}$ summarizing the strengths and limitations of such NGI modalities, identified PSMA-PET as the most promising modality, with lower inter-observer variability and higher degree of reproducibility. Nevertheless, this study also warns about pitfalls of this technique, such as the possible overestimation of lymph node detection sensitivity, encouraging randomized clinical trials investigating the role of NGI in combination with MDT in this setting. As a successful treatment relies on accurate imaging, the employment of NGI becomes mandatory in the era of high-precision medicine. ${ }^{22}$ Comparisons of standard and modern imaging methods have always shown the superiority of the latter, ${ }^{21}$ which are expected to replace conventional imaging in the course of a few years (Table 1). At present, the available evidence on their improved detection capability over standard imaging is not mature enough to include them in guidelines, which still prioritize traditional techniques to evaluate PCa metastatic burden. ${ }^{1}$ Clinical trials evaluating the benefits of using NGI to treat locally OMPC may clear their benefits, not only merely evaluating their diagnostic accuracy, but also considering their impact on oncological outcomes.

\section{New Drugs in OMPC}

In recent years, combinatorial approaches involving new drugs or already available systemic agents are revolutionizing the treatment of metastatic PCa. In the following, possible systemic treatment strategies for OMPC patients offered by the new target therapies emerging either in combination with or as an ADT substitute will be presented.

Historically, ADT is recommended as the standard of care for the general population of patients with metastatic $\mathrm{PCa}(\mathrm{mPCa})$ regardless of metastatic burden. In general, since the potential for ADT as a standalone therapy has reached a plateau, the next wave of therapeutic investigation will be focused on novel combinatorial approaches including radiotherapy, chemotherapy, second generation antiandrogens and immunotherapy. The most important findings on novel combinatory therapies derive from several recent phase II/III trials (Table 2). Notably, most of these trials include $\mathrm{mPCa}$ patients regardless of disease burden and timing of metastatic occurrence (eg synchronous vs metachronous).

As mentioned above, especially in patients with comorbidities, MDT is performed in order to delay ADT. In fact, several studies report that such aggressive systemic treatment has not a significant effect on OS gain in the oligometastatic setting. ${ }^{30}$

Indeed, since 2015, the addition of Docetaxel to ADT was demonstrated to confer survival benefit in men with $\mathrm{mPCa}$ not previously treated with ADT; conversely, no OS benefit from docetaxel addition to ADT was discerned in the low-volume disease both in the GETUG-AFU 15 (NCT00104715) and CHARTEED (NCT00309985) trials. ${ }^{30,31}$

These data are confirmed by the recent long-term survival analysis of the randomized Phase III CHARTEED trial by Kyriakopoulos et al. ${ }^{32}$ With an updated median follow-up up of 53.7 months the study confirmed the absence of any OS benefit for the low-volume disease subgroup of Docetaxel integration with ADT in metastatic 
Table I Comparison Between Conventional and Next-Generation Imaging Methods in the Setting of OMPC

\begin{tabular}{|c|c|c|c|}
\hline Type & Imaging Method & Strengths & Limitations \\
\hline \multirow[t]{2}{*}{ Conventional } & $\begin{array}{l}\text { Contrast-enhanced } \\
\text { thoraco-abdomino-pelvic } \\
\text { CT }\end{array}$ & $\begin{array}{l}>\text { Allows for whole-body } \\
\text { imaging }^{21} \\
>\text { Widely available and } \\
\text { affordable }^{21}\end{array}$ & $\begin{array}{l}>\text { Poor sensitivity and specificity for detection of LN mets } \\
\text { (sensitivity }<40 \%)^{16,18} \\
>\text { Suboptimal for detection of bone mets }\end{array}$ \\
\hline & $\begin{array}{l}{ }^{99 m} \text { Tc-MDP bone } \\
\text { scintigraphy }\end{array}$ & $\begin{array}{l}\text { > Consistency for classification of } \\
\text { MI vs } \text { M0 disease }^{21} \\
>\text { Most widely used method to } \\
\text { detect } \mathrm{BMs}^{21} \\
>\text { Widely available and } \\
\text { affordable }\end{array}$ & $>$ Misses metastatic lesions in bone marrow ${ }^{21}$ \\
\hline \multirow[t]{4}{*}{$\begin{array}{l}\text { Next } \\
\text { generation }\end{array}$} & Fluciclovine $\left({ }^{18} \mathbf{F}\right)$-PET & $\begin{array}{l}>\text { As good as choline-PET } \\
>\text { Identify both bony and soft }^{12} \\
\text { tissue lesions }^{12}\end{array}$ & $>$ Accuracy depends on PSA levels ${ }^{12}$ \\
\hline & ${ }^{18} \mathrm{~F} /{ }^{\prime \prime} \mathrm{C}$-choline PET/CT & $\begin{array}{l}>\text { Good specificity }(92-95 \%) \text { in } \\
\text { LN mets }{ }^{77,78}\end{array}$ & $\begin{array}{l}>\text { LNs: Modest sensitivity in detecting LN mets }(49.2- \\
62 \%)^{12} \\
>\text { High false positive rates with reactive } L_{N s^{12}} \\
>\text { Reduced sensitivity with low PSA values }{ }^{12}\end{array}$ \\
\hline & ${ }^{68}$ Ga-PSMA PET/CT & $\begin{array}{l}>\text { Superior detection rates } \\
\text { compared to other PET tracers }^{12} \\
>\text { Able to identify small lesions at } \\
\text { low PSA values }\end{array}$ & $\begin{array}{l}>\text { High false negative rates at low PSA values }{ }^{12} \\
>\text { Additional studies are needed to confirm results }\end{array}$ \\
\hline & WB-MRI & $\begin{array}{l}>\text { High sensitivity and specificity } \\
(>98 \%)^{12} \\
>\text { High inter-observer } \\
\text { agreement }{ }^{21,22} \\
>\text { No exposure to ionizing } \\
\text { radiations }{ }^{\prime \prime}\end{array}$ & $\begin{array}{l}>\text { Long scanning time, inter-scanner variability, } \\
\text { susceptibility to motion and other artefacts, high costs }{ }^{17} \\
>\text { Not widely used at present }{ }^{12}\end{array}$ \\
\hline
\end{tabular}

Abbreviations: IIC, carbon II; I8F-NaF, I8F-sodium fluoride; 99mTc-MDP, technetium medronic acid; CT, computed tomography; LN, lymph node; met, metastasis; MRI, magnetic resonance imaging; PET, positron emission tomography; PSMA, prostate-specific membrane antigen.

hormone-sensitive PCa (mHSPC) patients, while benefit was maintained with high volume disease. To note is that the majority of the patients of this study presented a de novo metastatic disease. Interestingly, in the STAMPEDE (NCT00268476) trial, Abiraterone and Prednisone addition to ADT demonstrated a statistically significant OS gain both in the high- and low-risk cohorts according to LATITUDE criteria. ${ }^{33}$ Same tendency in OS was reported when the CHAARTED criteria were applied to high- and low-volume groups. These preliminary analyses might suggest that Abiraterone addition to ADT might be effective not only for the overall population but also for the low risk/volume or oligometastatic patients with mHSPC. Some of the main pitfalls of Abiraterone are represented by its cost-effectiveness (compared to MDT and/or Docetaxel) and by the related side-effects such as hypertension, hypokalemia, and elevated liver enzymes levels. ${ }^{33}$ As a consequence, Abiraterone can be considered when the financial aspect is secondary and in patients who wish to avoid chemotherapy or to minimize hospital visits. Another second generation antiandrogen is Enzalutamide.

A recent interim analysis of the ENZAMET (NCT02446405) trial by Sweeney et al, ${ }^{34}$ demonstrated that the addition of Enzalutamide for metachronous patients improved the 3 -yr OS in the whole cohort $(83 \%$ vs $89 \%$ ) with an augmented efficacy ( $83 \%$ vs $92 \%)$ for the low-volume subset according to the CHARTEED criteria. Similar findings were reported in the TITAN trial (NCT02489318), investigating the benefits of adding Apalutamide to testosterone suppression in mHSPC. ${ }^{35}$ In this study, including 1052 men with mHSPC randomized to placebo or Apalutamide, $63 \%$ and $37 \%$ presented with 
Table 2 Summary of Some of the Most Promising New Target Therapies Emerging Either in Combination with or as an ADT Substitute in the Treatment of Hormone-Sensitive Oligometastatic Prostate Cancer

\begin{tabular}{|c|c|c|c|c|c|c|c|}
\hline Drug(s) & Clinical Trials & Phase & $\begin{array}{l}\text { Start- } \\
\text { End } \\
\text { Date }\end{array}$ & Status & $\mathbf{N}$ & Benefits & Limitations \\
\hline \multirow[t]{2}{*}{ Docetaxel } & $\begin{array}{c}\text { GETUG- } \\
\text { AFU 15 } \\
\text { (Docetaxel + } \\
\text { ADT) } \\
\text { NCT001047/5 }\end{array}$ & III & $\begin{array}{c}2004- \\
2011\end{array}$ & Completed & 385 & $\begin{array}{l}\text { > Improvement of b-PFS, } \\
\text { c-PFS and PSA response }\end{array}$ & $\begin{array}{l}>\text { No OS benefit for both } \\
\text { low- and high- volume } \\
\text { disease }\end{array}$ \\
\hline & $\begin{array}{l}\text { CHARTEED }^{31} \\
\text { (Docetaxel + } \\
\text { ADT) } \\
\text { NCT00309985 }\end{array}$ & III & $\begin{array}{c}2006- \\
2015\end{array}$ & $\begin{array}{l}\text { Active, not } \\
\text { recruiting }\end{array}$ & 790 & $\begin{array}{l}>\text { Benefit in OS in high- } \\
\text { volume disease }\end{array}$ & $\begin{array}{l}>\text { No OS benefit in low- } \\
\text { volume disease }\end{array}$ \\
\hline Abiraterone & $\begin{array}{l}\text { STAMPEDE } \\
(\text { arm G) } \\
\text { (Abiraterone + }^{33} \\
\text { Prednisone + } \\
\text { ADT) } \\
\text { NCT00268476 }\end{array}$ & II-III & $\begin{array}{c}2005- \\
2024\end{array}$ & Recruiting & 1003 & $\begin{array}{l}>\text { OS gain both in the low- } \\
\text { and in the high-risk and in } \\
\text { the low- and high- volume }\end{array}$ & $\begin{array}{l}\text { > Cost-effectiveness } \\
\text { (compared to Docetaxel) } \\
\text { > Side effects (hypertension, } \\
\text { hypokalemia, elevated liver } \\
\text { enzymes levels) } \\
\text { > Some patients had } \\
\text { synchronous disease }\end{array}$ \\
\hline \multirow[t]{2}{*}{ Enzalutamide } & $\begin{array}{l}\text { ENZAMET }^{34} \\
\text { (Enzalutamide + } \\
\text { ADT) } \\
\text { NCT02446405 }\end{array}$ & III & $\begin{array}{c}2014- \\
2023\end{array}$ & $\begin{array}{l}\text { Active, not } \\
\text { recruiting }\end{array}$ & 1125 & $\begin{array}{l}\text { > Improvement of 3-yr OS } \\
\text { for metachronous patients in } \\
\text { the whole cohort } \\
>\text { Augmented efficacy for the } \\
\text { low-volume subset }\end{array}$ & $\begin{array}{l}\text { > No clear OS benefit } \\
\text { among men receiving } \\
\text { concurrent Docetaxel in } \\
\text { high-volume disease } \\
\text { > Some patients had } \\
\text { synchronous disease }\end{array}$ \\
\hline & $\begin{array}{c}\text { ARCHES }^{36,37} \\
\text { (Enzalutamide + } \\
\text { ADT) } \\
\text { NCT02677896 }\end{array}$ & III & $\begin{array}{c}2016- \\
2018\end{array}$ & $\begin{array}{l}\text { Active, not } \\
\text { recruiting }\end{array}$ & 1150 & $\begin{array}{l}>\text { Reduced risk of metastatic } \\
\text { progression or death in low- } \\
\text { volume disease and/or prior } \\
\text { Docetaxel }\end{array}$ & $\begin{array}{l}>\text { The use of rPFS instead of } \\
\text { the more widely used OS } \\
\text { index } \\
>\text { Some patients had } \\
\text { synchronous disease }\end{array}$ \\
\hline Apalutamide & $\begin{array}{l}\text { TITAN }^{35} \\
\text { (testosterone } \\
\text { suppression }+ \\
\text { Apalutamide) } \\
\text { NCT024893/8 }\end{array}$ & III & $\begin{array}{c}2015- \\
2020\end{array}$ & $\begin{array}{l}\text { Active, not } \\
\text { recruiting }\end{array}$ & 1052 & $\begin{array}{l}>\text { Benefit across all } \\
\text { subgroups of patients }\end{array}$ & $\begin{array}{l}\text { > Small size of certain } \\
\text { patients' subgroups }\end{array}$ \\
\hline Durvalumab & $\begin{array}{l}\text { POSTCARD } \\
\text { (SBRT } \pm \\
\text { Durvalumab) } \\
\text { NCT03795207 }\end{array}$ & II & $\begin{array}{c}2019- \\
2024\end{array}$ & Recruiting & $\begin{array}{c}96 \\
\text { (estimated) }\end{array}$ & $\begin{array}{l}>\text { Expected enhancement of } \\
\text { immune response }\end{array}$ & $>$ Results expected by 2024 \\
\hline \multirow[t]{2}{*}{ Radium-223 } & $\begin{array}{c}\text { RROPE } \\
\text { (EBRT + } \\
\text { Radium-223) } \\
\text { NCT033044/8 }\end{array}$ & ॥ & $\begin{array}{c}2018- \\
2022\end{array}$ & $\begin{array}{l}\text { Active, not } \\
\text { recruiting }\end{array}$ & 20 & $\begin{array}{l}>\text { Expected delay of ADT } \\
\text { start }\end{array}$ & > Results expected by 2022 \\
\hline & $\begin{array}{c}\text { RAVENS }^{42} \\
(\text { SABR } \pm \\
\text { Radium-223) } \\
\text { NCT04037358 }\end{array}$ & II & $\begin{array}{c}2019- \\
2024\end{array}$ & Recruiting & $\begin{array}{c}64 \\
\text { (estimated) }\end{array}$ & $\begin{array}{l}>\text { Expected aadvantage of } \\
\text { combining SABR and } \\
\text { Radium- } 223\end{array}$ & > Results expected by 2024 \\
\hline
\end{tabular}

(Continued) 
Table 2 (Continued).

\begin{tabular}{|c|c|c|c|c|c|c|c|}
\hline Drug(s) & Clinical Trials & Phase & $\begin{array}{l}\text { Start- } \\
\text { End } \\
\text { Date }\end{array}$ & Status & $\mathbf{N}$ & Benefits & Limitations \\
\hline \multirow[t]{2}{*}{${ }^{177}$ Lu-PSMA } & $\begin{array}{l}\text { PILOT } \\
\text { STUDY }^{43}\end{array}$ & I-II & $\begin{array}{c}2018- \\
2019\end{array}$ & Completed & 10 & $\begin{array}{l}>\text { Feasible and safe treatment } \\
\text { modality in patients with } \\
\text { low-volume }\end{array}$ & $\begin{array}{l}\text { > Low-volume disease } \\
\text { could lead to unfavourable } \\
\text { radioligand distribution to } \\
\text { the organs at risk } \\
>\text { Small cohort* }\end{array}$ \\
\hline & $\begin{array}{l}\text { BULLSEYE }^{44} \\
\left({ }^{177} \text { Lu-PSMA }\right) \\
\text { NCT04443062 }\end{array}$ & II & $\begin{array}{c}2020- \\
2024\end{array}$ & Recruiting & $\begin{array}{c}58 \\
\text { (estimated) }\end{array}$ & $\begin{array}{l}\text { > Validation of results } \\
\text { obtained in the pilot study }\end{array}$ & > Results expected by 2024 \\
\hline
\end{tabular}

Notes: *Results refer to a previously published prospective pilot study ${ }^{40}$.

Abbreviations: ADT, androgen deprivation therapy; b-PFS, biochemical progression-free survival; c-PFS, clinical progression-free survival; EBRT, external-beam RT; OS, overall survival; PSA, prostate-specific antigen; PSMA, prostate-specific membrane antigen; r-PFS, radiographic progression-free survival; RT, radiotherapy; SABR, stereotactic ablative RT; SBRT, stereotactic body RT.

high- and low-volume disease, respectively; $11 \%$ had Docetaxel prior to enrollment (not concurrently); $86 \%$ had de novo metastases. Updated data with a median follow-up of 44.0 months revealed that addition of Apalutamide resulted in a benefit across all subgroups, with an overall hazard ratio (HR) for the OS of 0.65 (95\% confidence interval: $0.53-0.79$ ). Similar promising results for low-volume metastatic patients are reported by ARCHES multinational, double-blind, phase III trial (NCT02677896), wherein 1150 men with mHSPC received Enzalutamide vs placebo $+\mathrm{ADT}^{36}$ Enzalutamide addition was shown to significantly reduce the risk of metastatic progression or death over-time in men with low-volume disease and/or prior Docetaxel. ${ }^{33,37}$ Sathianathen et $\mathrm{al}^{38}$ in a recent metanalysis analyzed data from GETUG-AFU15, CHAARTED, LATITUDE, ENZAMET, and TITAN trials based on volume of disease. This subgroup analysis demonstrated how, for low-volume disease, only Enzalutamide treatment resulted in an improved survival and had the lowest absolute HR compared to ADT (HR 0.38, 95\% CI 0.20-0.68). Another area of rapid development in PCa research is the use of immunotherapy; unfortunately, several studies demonstrated that the response to immunotherapy is less robust in $\mathrm{PCa}$ than other solid malignancies. ${ }^{39,40}$ This could be related to some peculiar $\mathrm{PCa}$ characteristics, including reduced T-cell infiltration, downregulated major histocompatibility complex expression, and lower expression of programmed death-ligand (PD-L1). ${ }^{41}$ In the ongoing Phase II POSTCARD trial (NCT03795207), oligometastatic patients are randomized to receive SBRT \pm Durvalumab in a 2:1 ratio. The rationale behind this study, whose definitive results are expected by the end of 2023, is that Durvalumab will enhance immune response following SBRT targeting oligometastatic lesions.

Radiopharmaceuticals are systemic radioisotopes that deliver a high dose of radiation to multiple sites and represent a valid option in particular in bone metastases. RROPE trial (NCT03304418) is a Phase II, open label, single arm, and prospective study enrolling hormone therapy-naïve men with OMPC to the bone. The study will test if treating the primary tumor sites and 5 or fewer sites of bone-only metastases with external beam radiation with concomitant systemic Radium-223 allows to delay ADT start. Estimated primary completion date is for the end of 2022. A study investigating the role of radiopharmaceuticals in the oligometastatic setting is the RAVENS trial (NCT04037358). This phase II, nonblinded, randomized study compares $\mathrm{SABR} \pm$ Radium223 in OMPC patients with 3 or less metastases and at least one bone localization. The primary hypothesis is that SABR + Radium-223 will increase median progression-free survival (PFS) in the SABR + Radium-223 arm respect to SABR alone. Estimated primary completion date is expected for mid-2024. ${ }^{42}$

A small cohort pilot study by Privè et $\mathrm{al}^{43}$ indicated a potential favorable role for ${ }^{177} \mathrm{Lu}-\mathrm{PSMA}$ in patients with mHSPC with low-volume metastatic disease ( $\leq 10$ lesions) and good PSMA uptake on PET imaging. The ADT was postponed for all 10 patients, which maintained good quality of life. Half of them showed a PSA response of more than $50 \%$ and one patient had a complete radiological response. These 
promising results led to the development of the multicenter, open-label, randomized controlled BULLSEYE trial (NCT04443062). The rationale is to test whether ${ }^{177} \mathrm{Lu}-$ PSMA is an effective treatment in OMPC in the hormone sensitive setting in terms of PFS improvement and ADT delay. $^{44}$

As of today, combination therapy with either Abiraterone, Enzalutamide, or Apalutamide provides a significant OS benefit when compared with ADT alone. However, more solid data on novel combinatorial systemic approaches and their potential coexistence with MDTs will be provided by several ongoing trials that are trying to shed the light on this matter.

\section{Novel Biomarkers in OMPC}

From a biological point of view, the oligometastatic state exhibits a peculiar behavior when compared with a heavy burden state of disease. As previously mentioned, the existence of distinct underlying molecular mechanisms characterizing the oligometastatic state has been hypothesized. ${ }^{45}$ The use of PSA alone seems to be excessively limiting in the identification of the true oligometastatic patient. As a consequence, several efforts have been made in order to identify dependable additional biomarkers for the choice of the best treatment option(s). ${ }^{46-50}$ The biology of metastatic progression relies on multiple factors that mediate the cross-talk between cancer cells and their local or distant environment including cytokines, exosomes and miRNAs, which post-transcriptionally affect gene expression and several steps in the metastatic cascade. In general, several paths exists through which metastases may originate: (i) synchronous seeding (from the primary tumor), (ii) metachronous seeding (from other metastases) and (iii) self-seeding (return to the site of origin). ${ }^{51}$

It has been speculated that malignant clones in oligometastases do not have the biological requirements to infiltrate multiple sites and lead to a high burden disease ${ }^{52,53}$ In fact, while these have the classical ability of metastatic clones to evade the immune system and disseminate through the body, they lack some of the classic features of malignancy, which translates into a lower metastatic potential. ${ }^{54}$ Assuming the above, local ablative treatments appear as the most reasonable approaches for the patients in this setting, allowing to avoid or defer systemic therapies and their related side effects. In this view, the identification of reliable biomarkers could foster the correct stratification of metastatic PCa patients and complement the information provided by imaging modalities.

Historically, histopathological examinations have represented the ground truth for the definitive diagnosis of PCa. However, a single bioptic assessment can be inadequate to depict the dynamics of the tumor and its underlying biology over time. Liquid biopsy is emerging as a valuable candidate to fill this void, allowing to overcome the static and invasive bioptic approach ${ }^{55,56}$ Notwithstanding the lack of validated biomarkers in OMPC, several liquid biopsy-derived analytes are emerging as promising candidates to boost the development of tailored treatments. Specifically, some of the most promising ones are circulating tumor cells (CTCs), exosomes and circulating cell-free DNA (cfDNA) such as circulating tumor DNA (ctDNA), and miRNAs ${ }^{57,58}$ (Table 3).

In detail, CTCs represent cancer cell clones originating from a tumor site and can be found in the bloodstreams both as single agents or clusters. ${ }^{59,60}$ Two recent studies reported their promising role as biomarkers representing the metastases mutational content, thus offering a real time monitoring through their sequencing. In addition, an exploratory study on a small cohort demonstrated that pre- and post-operative CTCs enumeration outperformed PSA as prognostic factor for oncological outcomes at 6 months. ${ }^{61,62}$ A major drawback of CTCs is represented by their rarity in the bloodstream and their isolation still represents a limiting step to their clinical implementation. ${ }^{63-66}$ Similarly to CTCs, ctDNA can be used as a biomarker to characterize the mutational and epigenomic landscape in advanced solid tumors. ctDNA originates from apoptotic and necrotic cells and comprises both genomic and mitochondrial DNA. ${ }^{67}$ It is nowadays well accepted that ctDNA concentration in plasma is highly related to both tumor size and clinical stage. Due to its relatively short half-life, ctDNA appears as a suitable agent to provide a real-time monitoring of the malignancy status. ${ }^{68,69}$ Despite early promising results, a major barrier to a wider implementation of ctDNA as a prognostic biomarker is represented by its challenging measurement and the controversial choice of the main source (eg serum, plasma) of such agent. Among different available candidate biomarkers, RNA-based analytes show an advantage over the DNAbased ones thanks to their higher tissue- and diseasespecificity, which make them more appropriate descriptors of disease status. In this context, mi-RNAs are short non coding transcripts participating in gene regulation at a posttranscriptional level (cell growth alteration, apoptotic process, metastasis formation and cell differentiation). ${ }^{70}$ Since several miRNAs are highly tissue-specific and participate in distinct pathways to elicit different cellular effects that are dependent on the cell type and target expression and their function has been found controversial in several cancers. ${ }^{71-73}$ 
Table 3 Summary of Some of the Most Promising Biomarkers for the Identification of the True Oligometastatic Patient. Strengths and Limitations for Each of the Described Analytes are Reported

\begin{tabular}{|c|c|c|c|}
\hline Biomarker & Definition & Strengths & Limitations \\
\hline $\begin{array}{l}\text { Circulating } \\
\text { Tumor Cells } \\
\text { (CTCs) }\end{array}$ & $\begin{array}{l}\text { Cancer cell clones originating from a tumor } \\
\text { site }\end{array}$ & $\begin{array}{l}\text { > real time monitoring of metastases } \\
\text { mutational content } \\
>\text { in exploratory studies outperformed } \\
\text { PSA as prognostic factor for oncological } \\
\text { outcomes at } 6 \text { months } 57,58\end{array}$ & $\begin{array}{l}>\text { rarity in the bloodstream } \\
>\text { difficult isolation } \\
{ }^{62}\end{array}$ \\
\hline $\begin{array}{l}\text { Circulating } \\
\text { Tumor DNA } \\
\text { (ctDNA) }\end{array}$ & $\begin{array}{l}\text { Originates from apoptotic and necrotic } \\
\text { cells and comprises both genomic and } \\
\text { mitochondrial DNA }\end{array}$ & $\begin{array}{l}\text { > plasma concentration highly related to } \\
\text { both tumor size and clinical stage }{ }^{64} \\
>\text { short half-life, suitable agent for } \\
\text { disease real-time monitoring }\end{array}$ & $\begin{array}{l}>\text { challenging measurement }{ }^{65} \\
>\text { choice of the main source is } \\
\text { controversial (plasma vs serum) }{ }^{65}\end{array}$ \\
\hline $\begin{array}{l}\text { Micro Ribo- } \\
\text { Nucleic Acid } \\
\text { (miRNA) }\end{array}$ & $\begin{array}{l}\text { Short non-coding transcripts of } 17-25 \\
\text { nucleotides, participating in gene regulation }\end{array}$ & $\begin{array}{l}>\text { high stability in biological fluids } \\
>\text { baseline expression associated with } \\
\text { CTCs and } 28 \text {-weeks PSA response } \\
>\text { several studies available on their role } \\
\text { in } \mathrm{PCa}^{72-75}\end{array}$ & $\begin{array}{l}>\text { function can be controversial in } \\
\text { different cancers }{ }^{67-69} \\
>\text { a strong signature needs to be } \\
\text { validated yet } \\
>\text { lacking of standard procedures for } \\
\text { isolation and storage }\end{array}$ \\
\hline
\end{tabular}

Abbreviations: CTC, circulating tumor cell; ctDNA, circulating tumor DNA; DNA, deoxyribonucleic acid; miRNA, micro ribo-nucleic acid; PCa, prostate cancer; PMPC, polimetastatic prostate cancer; PSA, prostate specific antigen.

A recent study reported how expression levels of some baseline plasma miRNA were significantly associated with CTCs number and with the 28 -weeks PSA response. ${ }^{74}$ In general, awareness is mounting about the role of the miRNA in the communication between cancer cells and their environment, and ultimately in the miRNA mediated metastatic progression. ${ }^{75}$ Based on the available evidence, several studies have investigated the role of miRNAs as potential biomarkers in PCa carcinogenesis and in the clinical course of the disease. ${ }^{76-80}$ Overall, a deeper understanding of the molecular mechanism of the oligometastatic clinical entity could unravel novel suitable biomarkers to refine risk stratification and to reduce overtreatment, with technologies such as liquid biopsies and next-generation sequencing expected to play an important role in the clinical setting, paving the way towards a wider approach of personalized medicine.

\section{Conclusion}

This paper offers an overview of the recent available literature describing the oligometastatic scenario. Most recent breakthroughs in this setting relied on the increased number of approved treatments with various implications for surgery, radiotherapy, and systemic therapy. As of today, no level one evidence exists on the management of hormone-sensitive OMPC patients. In the era of personalized medicine another important issue is represented by the correct patients' selection in which NGI and novel biomarkers could provide deeper insights. Perfecting the definition of oligometastatic disease in PCa could offer a unique opportunity to better define the therapeutic window. An important question on OMPC revolves around the existence of an underlying biological background. In fact, since the number of metastases invariably increases over time, the oligometastatic state may simply represent a transient phase of the natural course of the disease for different biomarkers that might reflect systemic tumor burden. In conclusion, it might be speculated that novel combinatorial regimens will be approved soon, but beside clinical considerations, other factors such as treatment access, financial burden, and logistics will impact the final treatment choice. As new data accumulate, tailored treatments will be enhanced allowing to discern among patients who are in need of treatment intensification, those who can be managed conservatively, and those who can be considered for cure.

\section{Abbreviations}

${ }^{18}$ F-FACBC, 18F-fluoroethylcholine (18F-Cho), trans1-amino-3-18F-fluorocyclobutanecarboxylic-acid; ${ }^{18} \mathrm{~F}-\mathrm{DC}$ FPyL, 2-(3-\{1-carboxy-5-[(6-[18F]fluoro-pyridine-3-carbonyl)-amino]-pentyl $\}$-ureido)-pentanedioic acid; ${ }^{99 \mathrm{~m}} \mathrm{Tc}$ MDP, technetium 99m-methylene diphosphonate; ADT, androgen deprivation therapy; APCCC, Advanced Prostate Cancer Consensus Conference; ASTRO, American Society for Radiation Oncology; CTC, circulating tumor cells; cfDNA, circulating free DNA; ctDNA, circulating tumor 
DNA; DCE, dynamic contrast-enhanced; DWI, diffusionweighted imaging; EAU, European Association of Urology; ENRT, elective nodal radiotherapy; ESTRO, European SocieTy for Radiotherapy and Oncology; HR, hazard ratio; MDT, metastasis-directed therapy; $\mathrm{mHSPC}$, metastatic hormone-sensitive $\mathrm{PCa} ; \mathrm{mPCa}$, metastatic $\mathrm{PCa}$; MRI, magnetic resonance imaging; $\mathrm{NCCN}$, national comprehensive cancer network; NGI, next-generation imaging; OMPC, oligometastatic prostate cancer; OS, overall survival; PCa, prostate cancer; $\mathrm{PET/CT}$, positron emission tomography/computed tomography; PFS, progression-free survival; PSA, prostate-specific antigen; PSMA, 68Gaprostate-specific membrane antigen; SBRT, stereotactic body radiotherapy; SIOG, International Society of Geriatric Oncology; SPECT, single-photon emission computed tomography; USPIO, ultra-small superparamagnetic iron oxide; WB-MRI, whole body MRI.

\section{Acknowledgments}

Mattia Zaffaroni received a research grant by the European Institute of Oncology-Cardiologic Center Monzino Foundation (FIEO-CCM), with a project entitled "Proton therapy vs photon-based IMRT for parotid gland tumors: a model based approach with Normal Tissue Complication Probability (NTCP)" outside the current study. Stefania Volpe is a $\mathrm{PhD}$ student within the European School of Molecular Medicine (SEMM), Milan, Italy. This work was also partially supported by the Italian Ministry of Health with Ricerca Corrente and $5 \times 1000$ funds and by a research grant from the Associazione Italiana per la Ricerca sul Cancro (AIRC) entitled "Radioablation \pm hormonotherapy for prostate cancer oligorecurrences (RADIOSA trial): potential of imaging and biology" registered at ClinicalTrials. govNCT03940235, approved by the Ethics Committee of IRCCS Istituto Europeo di Oncologia and Centro Cardiologico Monzino (IEO-997). The sponsors did not play any role in the study design, collection, analysis and interpretation of data, nor in the writing of the manuscript, nor in the decision to submit the manuscript for publication. The author reports no conflicts of interest in this work.

\section{Disclosure}

Professor Barbara Alicja Jereczek-Fossa report grants from AIRC, grants from FIEO-CCM \& FUV, grants from Accuray, personal fees from Janssen, personal fees from Ferring, personal fees from Bayer, personal fees from Roche, personal fees from Astellas, personal fees from Elekta, personal fees from Carl Zeiss, personal fees from Ipsen, personal fees from Accuray, personal fees from Iba, outside the submitted work. The authors report no other conflicts of interest in this work.

\section{References}

1. Tosoian JJ, Gorin MA, Ross AE, et al. Oligometastatic prostate cancer: definitions, clinical outcomes, and treatment considerations. Nat Rev Urol. 2017;14:15-25. doi:10.1038/nrurol.2016.175

2. Foster CC, Weichselbaum RR, Pitroda SP. Oligometastatic prostate cancer: reality or figment of imagination? Cancer. 2019;125:340-352. doi: $10.1002 /$ cncr. 31860

3. Fraser M, Koontz B, Emmenegger U, et al. What Is Oligometastatic Prostate Cancer? Eur Urol Focus. 2019;5:159-161. doi:10.1016/j. euf.2018.12.009

4. Sumiyoshi T, Chi KN, Wyatt AW. Clinical implications of genomic alterations in metastatic prostate cancer. Prostate Cancer Prostatic Dis. 2021;24:310-322. doi:10.1038/s41391-020-00308-x

5. Kothari G, Ost P, Cheung P, et al. Trends in management of oligometastatic hormone-sensitive prostate cancer. Curr Oncol Rep. 2019;21(43). doi:10.1007/s11912-019-0791-5

6. Lievens Y, Guckenberger M, Gomez D, et al. Defining oligometastatic disease from a radiation oncology perspective: an ESTRO-ASTRO consensus document. Radiother Oncol J Eur Soc Ther Radiol Oncol. 2020;148:157-166. doi:10.1016/j.radonc.2020.04.003

7. APCCC 2019: oligometastatic Prostate Cancer - definitions and Concepts. Available from: https://www.urotoday.com/conferencehighlights/apccc-2019/114616-apccc-2019-oligometastatic-prostatecancer-definitions-and-concepts.html. Accessed December 10, 2021.

8. Rogowski P, Roach M, Schmidt-Hegemann NS, et al. Radiotherapy of oligometastatic prostate cancer: a systematic review. Radiat Oncol. 2021;16(50):1-6. doi:10.1186/s13014-021-01776-8

9. Marvaso G, Volpe S, Pepa M, et al. Oligorecurrent prostate cancer and stereotactic body radiotherapy: where are we now? A systematic review and meta-analysis of prospective studies. Eur Urol Open Sci. 2021;27:19-28. doi:10.1016/j.euros.2021.02.008

10. Mazzola R, Francolini G, Triggiani L, et al. Metastasis-directed Therapy (SBRT) Guided by PET-CT 18F-CHOLINE Versus PET-CT 68Ga-PSMA in Castration-sensitive Oligorecurrent Prostate Cancer: a Comparative Analysis of Effectiveness. Clin Genitourin Cancer. 2021;19:230-236. doi:10.1016/j.clgc.2020.08.002

11. Albisinni S, Tafuri A, Pirozzi M, et al. A systematic review of imaging-guided metastasis-directed therapy for oligorecurrent prostate cancer: revolution or devolution? Minerva Urol Nefrol;2020. 72. doi:10.23736/S0393-2249.19.03586-0

12. Sritharan K, Rieu R, Tree A. A narrative review of oligometastatic prostate cancer-an evolving paradigm. Ann Palliat Med. 2021;10:5969-5987. doi:10.21037/apm-20-1215

13. De Bleser E, Jereczek-Fossa BA, Pasquier D, et al. Metastasisdirected therapy in treating nodal oligorecurrent prostate cancer: a multi-institutional analysis comparing the outcome and toxicity of stereotactic body radiotherapy and elective nodal radiotherapy. Eur Urol. 2019;76:732-739. doi:10.1016/j.eururo.2019.0 7.009

14. Ost P, Reynders D, Decaestecker K, et al. Surveillance or metastasis-directed therapy for oligometastatic prostate cancer recurrence: a prospective, randomized, multicenter phase II trial. J Clin Oncol. 2018;36:446-453. doi:10.1200/JCO.2017.75.4853

15. Deek MP, Phillips RM, Tran PT. Local Therapies in Oligometastatic and Oligoprogressive Prostate Cancer. Semin Radiat Oncol. 2021;31:242-249. doi:10.1016/j.semradonc.2021.03.007 
16. Perez-Lopez R, Tunariu N, Padhani AR, et al. Imaging diagnosis and follow-up of advanced prostate cancer: clinical perspectives and state of the art. Radiology. 2019;292:273-286. doi:10.1148/ radiol.2019181931

17. Rao A, Vapiwala N, Schaeffer EM, Ryan CJ. Oligometastatic prostate cancer: a shrinking subset or an opportunity for cure? Am Soc Clin Oncol Educ Book. 2019;309-320. doi:10.1200/EDBK_239041

18. Hövels AM, Heesakkers RAM, Adang EM, et al. The diagnostic accuracy of CT and MRI in the staging of pelvic lymph nodes in patients with prostate cancer: a meta-analysis. Clin Radiol. 2008;63:387-395. doi:10.1016/j.crad.2007.05.022

19. Shen G, Deng H, Hu S, Jia Z. Comparison of choline-PET/CT, MRI, SPECT, and bone scintigraphy in the diagnosis of bone metastases in patients with prostate cancer: a meta-analysis. Skeletal Radiol. 2014;43:1503-1513. doi:10.1007/s00256-014-1903-9

20. Farolfi A, Koschel S, Murphy DG, Fanti S. PET imaging in urology: a rapidly growing successful collaboration. Curr Opin Urol. 2020; Publish Ahead of Print. doi:10.1097/MOU.0000000000000800

21. Lecouvet FE, Oprea-Lager DE, Liu Y, et al. Use of modern imaging methods to facilitate trials of metastasis-directed therapy for oligometastatic disease in prostate cancer: a consensus recommendation from the EORTC Imaging Group. Lancet Oncol. 2018;19:e534-e545. doi:10.1016/S1470-2045(18)30571-0

22. Farolfi A, Hadaschik B, Hamdy FC, et al. Positron emission tomography and whole-body magnetic resonance imaging for metastasis-directed therapy in hormone-sensitive oligometastatic prostate cancer after primary radical treatment: a systematic review. Eur Urol Oncol. 2021: S2588931121000377. doi:10.1016/j.euo.2021.02.003

23. Gillessen S, Attard G, Beer TM, et al. Management of Patients with Advanced Prostate Cancer: the Report of the Advanced Prostate Cancer Consensus Conference APCCC 2017. Eur Urol. 2018;73:178-211. doi:10.1016/j.eururo.2017.06.002

24. FDA approves new diagnostic imaging agent FLUCICLOVINE F-18 to detect recurrent prostate cancer « New Drug Approvals. Available from: https:/newdrugapprovals.org/2016/05/28/fda-approves-newdiagnostic-imaging-agent-fluciclovine-f-18-to-detect-recurrentprostate-cancer/. Accessed December 10, 2021.

25. Axumin ${ }^{\circledR}$ (fluciclovine F 18) injection | terms \& Conditions. Available from: https://www.axumin.com/sites/default/files/2018-03/ Axumin_PI_08_2016_Clean. Accessed December 10, 2021.

26. Kim EH, Siegel BA, Teoh EJ, Andriole GL. Prostate cancer recurrence in patients with negative or equivocal conventional imaging: a role for $18 \mathrm{~F}$-fluciclovine-PET/CT in delineating sites of recurrence and identifying patients with oligometastatic disease. Urol Oncol Semin Orig Investig. 2021;39:365.e9-365.e16.

27. Andriole GL, Kostakoglu L, Chau A, et al. The Impact of Positron Emission Tomography with ${ }^{18}$ F-Fluciclovine on the Treatment of Biochemical Recurrence of Prostate Cancer: results from the LOCATE Trial. J Urol. 2019;201:322-331. doi:10.1016/j.juro.2018.08.050

28. Woo S, Suh CH, Kim SY, Cho JY, Kim SH. The diagnostic performance of MRI for detection of lymph node metastasis in bladder and prostate cancer: an updated systematic review and diagnostic meta-analysis. Am J Roentgenol. 2018;210:W95-W109. doi:10.2214/AJR.17.18481

29. Padhani AR, Lecouvet FE, Tunariu N, et al. METastasis reporting and data system for prostate cancer: practical guidelines for acquisition, interpretation, and reporting of whole-body magnetic resonance imaging-based evaluations of multiorgan involvement in advanced prostate cancer. Eur Urol. 2017;71:81-92. doi:10.1016/j.eururo.2016.05.033

30. Sweeney CJ, Chen Y-H, Carducci M, et al. Chemohormonal Therapy in Metastatic Hormone-Sensitive Prostate Cancer. $N$ Engl J Med. 2015;373:737-746. doi:10.1056/NEJMoa1503747

31. Gravis G, Fizazi K, Joly F, et al. Androgen-deprivation therapy alone or with docetaxel in non-castrate metastatic prostate cancer (GETUG-AFU 15): a randomised, open-label, Phase 3 trial. Lancet Oncol. 2013;14:149-158. doi:10.1016/S1470-2045(12)70560-0
32. Kyriakopoulos CE, Chen Y-H, Carducci MA, et al. Chemohormonal therapy in metastatic hormone-sensitive prostate cancer: long-term survival analysis of the randomized phase III E3805 CHAARTED Trial. J Clin Oncol Off J Am Soc Clin Oncol. 2018;36:1080-1087. doi:10.1200/JCO.2017.75.3657

33. Barata PC, Sartor AO. Metastatic castration-sensitive prostate cancer: abiraterone, docetaxel, or .... Cancer. 2019;125:1777-1788. doi: $10.1002 /$ cncr.32039

34. Sweeney CJ, Martin AJ, Stockler MR, et al. Overall survival of men with metachronous metastatic hormone-sensitive prostate cancer treated with enzalutamide and androgen deprivation therapy. Eur Urol. 2021;80:275-279. doi:10.1016/j.eururo.2021.05.016

35. Davis ID, Martin AJ, Stockler MR, et al. Enzalutamide with standard first-line therapy in metastatic prostate cancer. $N$ Engl J Med. 2019;381:121-131. doi:10.1056/NEJMoa1903835

36. Armstrong AJ, Szmulewitz RZ, Petrylak DP, et al. ARCHES: a randomized, phase iii study of androgen deprivation therapy with enzalutamide or placebo in men with metastatic hormone-sensitive prostate cancer. $J$ Clin Oncol Off $J$ Am Soc Clin Oncol. 2019;37:2974-2986. doi:10.1200/JCO.19.00799

37. Armstrong AJ, Shore ND, Szmulewitz RZ, et al. Efficacy of Enzalutamide plus Androgen Deprivation Therapy in Metastatic Hormone-Sensitive Prostate Cancer by Pattern of Metastatic Spread: ARCHES Post Hoc Analyses. J Urol. 2021;205:1361-1371. doi:10.1097/JU.0000000000001568

38. Sathianathen NJ, Koschel S, Thangasamy IA, et al. Indirect comparisons of efficacy between combination approaches in metastatic hormone-sensitive prostate cancer: a systematic review and network meta-analysis. Eur Urol. 2020;77:365-372. doi:10.1016/j. eururo.2019.09.004

39. Madan RA, Gulley JL. Finding an immunologic beachhead in the prostate cancer microenvironment. $J$ Natl Cancer Inst. 2019;111:219-220. doi:10.1093/jnci/djy145

40. Zhao SG, Lehrer J, Chang SL, et al. The Immune Landscape of Prostate Cancer and Nomination of PD-L2 as a Potential Therapeutic Target. J Natl Cancer Inst. 2019;111:301-310. doi:10.1093/jnci/djy141

41. Patel D, McKay R, Parsons JK. Immunotherapy for Localized Prostate Cancer: the Next Frontier? Urol Clin North Am. 2020;47:443-456. doi:10.1016/j.ucl.2020.07.008

42. Hasan H, Deek MP, Phillips R, et al. A phase II randomized trial of RAdium-223 dichloride and SABR Versus SABR for oligomEtastatic prostate caNcerS (RAVENS). BMC Cancer. 2020;20(492). doi:10.1186/s12885-020-07000-2

43. Privé BM, Peters SMB, Muselaers CHJ, et al. Lutetium-177-PSMA -617 in Low-volume hormone-sensitive metastatic prostate cancer: a Prospective Pilot Study. Clin Cancer Res Off J Am Assoc Cancer Res. 2021;27:3595-3601. doi:10.1158/1078-0432.CCR-20-4298

44. Privé BM, Janssen MJR, van Oort IM, et al. Update to a randomized controlled trial of lutetium-177-PSMA in Oligo-metastatic hormone-sensitive prostate cancer: the BULLSEYE trial. Trials. 2021;22(768). doi:10.1186/s13063-021-05733-4

45. Kucharczyk MJ, Gravis G, Niazi T. The biology of oligometastatic prostate cancer: a different beast than polymetastatic prostate cancer. Eur Urol Focus. 2019;5:117-118. doi:10.1016/j.euf.2018.11.011

46. Lussier YA, Xing HR, Salama JK, et al. MicroRNA expression characterizes oligometastasis(es). PLoS One. 2011;6(e28650): e28650. doi:10.1371/journal.pone.0028650

47. Lussier YA, Khodarev NN, Regan K, et al. Oligo- and polymetastatic progression in lung metastasis(es) patients is associated with specific microRNAs. PLoS One. 2012;7(e50141):e50141. doi:10.1371/journal.pone.0050141

48. Joice GA, Rowe SP, Pienta KJ, Gorin MA. Oligometastatic prostate cancer: shaping the definition with molecular imaging and an improved understanding of tumor biology. Curr Opin Urol. 2017;27:533-541. doi:10.1097/MOU.0000000000000449 
49. Dhondt B, De Bleser E, Claeys T, et al. Discovery and validation of a serum microRNA signature to characterize oligo- and polymetastatic prostate cancer: not ready for prime time. World J Urol. 2019;37:2557-2564. doi:10.1007/s00345-018-2609-8

50. Zhang W, Wu Y, Zhang Z, et al. Controlling Nutritional Status score: a new prognostic indicator for patients with oligometastatic prostate cancer. Curr Probl Cancer. 2019;43:461-470. doi:10.1016/j. currproblcancer.2019.02.001

51. Sonpavde G. The biology of prostate cancer metastases: does oligo differ from polymetastatic? Curr Opin Urol. 2017;27:542-546. doi:10.1097/MOU.0000000000000434

52. Li Y, Tang Z-Y, Ye S-L, et al. Establishment of cell clones with different metastatic potential from the metastatic hepatocellular carcinoma cell line MHCC97. World J Gastroenterol. 2001;7:630-636. doi:10.3748/wjg.v7.i5.630

53. Uppal A, Wightman SC, Mallon S, et al. 14q32-encoded microRNAs mediate an oligometastatic phenotype. Oncotarget. 2015;6:3540-3552. doi:10.18632/oncotarget.2920

54. Reyes DK, Pienta KJ. The biology and treatment of oligometastatic cancer. Oncotarget. 2015;6:8491-8524. doi:10.18632/oncotarget.3455

55. Arancio W, Belmonte B, Castiglia M, Di Napoli A, Tripodo C. Tissue Versus Liquid Biopsy: opposite or Complementary? In: Russo A, Giordano A, Rolfo C editors. Liquid Biopsy in Cancer Patients: The Hand Lens for Tumor Evolution. Springer International Publishing; 2017:41-49. doi:10.1007/978-3-319-55661-1_4

56. Ghosh RK, Pandey T, Dey P. Liquid biopsy: a new avenue in pathology. Cytopathol off J Br Soc Clin Cytol. 2019;30:138-143. doi:10.1111/cyt.12661

57. Stelcer E, Konkol M, Głęboka A, Suchorska WM. Liquid Biopsy in Oligometastatic Prostate Cancer-A Biologist's Point of View. Front Oncol. 2019;9(775). doi:10.3389/fonc.2019.00775

58. Wang J, Ni J, Beretov J, et al. Exosomal microRNAs as liquid biopsy biomarkers in prostate cancer. Crit Rev Oncol Hematol. 2020;145 (102860):102860. doi:10.1016/j.critrevonc.2019.102860

59. Hegemann M, Stenzl A, Bedke J, et al. Liquid biopsy: ready to guide therapy in advanced prostate cancer? BJU Int. 2016;118:855-863. doi:10.1111/bju.13586

60. Gkountela S, Castro-Giner F, Szczerba BM, et al. Circulating Tumor Cell Clustering Shapes DNA Methylation to Enable Metastasis Seeding. Cell. 2019;176:98-112.e14. doi:10.1016/j.cell.2018.11.046

61. Faugeroux V, Lefebvre C, Pailler E, et al. An Accessible and Unique Insight into Metastasis Mutational Content Through Whole-exome Sequencing of Circulating Tumor Cells in Metastatic Prostate Cancer. Eur Urol Oncol. 2020;3:498-508. doi:10.1016/j.euo.2018.12.005

62. Mandel PC, Huland H, Tiebel A, et al. Enumeration and Changes in Circulating Tumor Cells and Their Prognostic Value in Patients Undergoing Cytoreductive Radical Prostatectomy for Oligometastatic Prostate Cancer-Translational Research Results from the Prospective ProMPT trial. Eur Urol Focus. 2021;7:55-62. doi:10.1016/j.euf.2019.05.008

63. Barriere G, Fici P, Gallerani G, et al. Circulating tumor cells and epithelial, mesenchymal and stemness markers: characterization of cell subpopulations. Ann Transl Med. 2014;2:109. doi:10.3978/j. issn.2305-5839.2014.10.04

64. Magbanua MJM, Solanki TI, Ordonez AD, Hsiao F, Park JW. Enumeration of Circulating Tumor Cells and Disseminated Tumor Cells in Blood and Bone Marrow by Immunomagnetic Enrichment and Flow Cytometry (IE/FC). Methods Mol Biol Clifton NJ. 1634;203-210:2017.
65. Togo S, Katagiri N, Namba Y, et al. Sensitive detection of viable circulating tumor cells using a novel conditionally telomerase-selective replicating adenovirus in non-small cell lung cancer patients. Oncotarget. 2017;8(21):34884-34895. doi:10.18632/oncotarget.16818

66. Mansilla C, Soria E, Ramírez N. The identification and isolation of CTCs: a biological Rubik's cube. Crit Rev Oncol Hematol. 2018;126:129-134. doi:10.1016/j.critrevonc.2018.03.027

67. Lowes LE, Bratman S, Dittamore R, et al. Circulating Tumor Cells (CTC) and Cell-Free DNA (cfDNA) Workshop 2016: scientific Opportunities and Logistics for Cancer Clinical Trial Incorporation. Int J Mol Sci. 2016;17:E1505. doi:10.3390/ijms17091505

68. Elshimali YI, Khaddour H, Sarkissyan M, Wu Y, Vadgama JV. The clinical utilization of circulating cell free DNA (CCFDNA) in blood of cancer patients. Int J Mol Sci. 2013;14:18925-18958. doi:10.3390/ ijms140918925

69. Salvi S, Gurioli G, De Giorgi U, et al. Cell-free DNA as a diagnostic marker for cancer: current insights. OncoTargets Ther. 2016;9:6549-6559. doi:10.2147/OTT.S100901

70. Esquela-Kerscher A, Slack FJ. Oncomirs - microRNAs with a role in cancer. Nat Rev Cancer. 2006;6:259-269. doi:10.1038/nrc1840

71. Zabolotneva AA, Zhavoronkov A, Garazha AV, Roumiantsev SA, Buzdin AA. Characteristic patterns of microRNA expression in human bladder cancer. Front Genet. 2012;3(310):2521.

72. Hessvik NP, Sandvig K, Llorente A. Exosomal miRNAs as Biomarkers for Prostate Cancer. Front Genet. 2013;4(36). doi:10.3389/fgene.2013.00036

73. Mulrane L, McGee SF, Gallagher WM, O'Connor D. miRNA dysregulation in breast cancer. Cancer Res. 2013;73:6554-6562. doi:10.1158/0008-5472.CAN-13-1841

74. Cheng $\mathrm{HH}$, Plets $\mathrm{M}$, Li H, et al. Circulating microRNAs and treatment response in the Phase II SWOG S0925 study for patients with new metastatic hormone-sensitive prostate cancer. The Prostate. 2018;78(2):121-127. doi:10.1002/pros.23452

75. Dhondt B, Rousseau Q, De Wever O, Hendrix A. Function of extracellular vesicle-associated miRNAs in metastasis. Cell Tissue Res. 2016;365:621-641. doi:10.1007/s00441-016-2430-x

76. Al-Kafaji G, Said HM, Alam MA, Al Naieb ZT. Blood-based microRNAs as diagnostic biomarkers to discriminate localized prostate cancer from benign prostatic hyperplasia and allow cancer-risk stratification. Oncol Lett. 2018;16:1357-1365. doi:10.3892/ ol.2018.8778

77. Bhagirath D, Yang TL, Bucay N, et al. microRNA-1246 Is an Exosomal Biomarker for Aggressive Prostate Cancer. Cancer Res. 2018;78(7):1833-1844. doi:10.1158/0008-5472.CAN-17-2069

78. Paziewska A, Mikula M, Dabrowska M, et al. Candidate diagnostic miRNAs that can detect cancer in prostate biopsy. Prostate. 2018;78 (3):178-185. doi:10.1002/pros.23427

79. Tu J, Peng Q, Shen Y, et al. Identification of biomarker microRNA-mRNA regulatory pairs for predicting the docetaxel resistance in prostate cancer. J Cancer. 2019;10:5469-5482. doi:10.7150/ jca. 29032

80. Cochetti G, Vermandois JA, Maulà V, et al. Role of miRNAs in prostate cancer: do we really know everything? Urol Oncol Semin Orig Investig. 2020;38:623-635. 


\section{Publish your work in this journal}

Cancer Management and Research is an international, peer-reviewed open access journal focusing on cancer research and the optimal use of preventative and integrated treatment interventions to achieve improved outcomes, enhanced survival and quality of life for the cancer patient.
The manuscript management system is completely online and includes a very quick and fair peer-review system, which is all easy to use. Visit http://www.dovepress.com/testimonials.php to read real quotes from published authors.

Submit your manuscript here: https://www.dovepress.com/cancer-management-and-research-journal 